\title{
Possible Association of IL-4 VNTR Polymorphism with Susceptibility to Preeclampsia
}

\author{
Saeedeh Salimi, ${ }^{1,2}$ Milad Mohammadoo-Khorasani, ${ }^{1,2}$ Minoo Yaghmaei, ${ }^{3}$ \\ Mojgan Mokhtari, ${ }^{3}$ and Maryam Moossavi ${ }^{4}$ \\ ${ }^{1}$ Cellular and Molecular Research Center, Zahedan University of Medical Sciences, Zahedan 9816743111, Iran \\ ${ }^{2}$ Department of Clinical Biochemistry, School of Medicine, Zahedan University of Medical Sciences, Zahedan 9816743111, Iran \\ ${ }^{3}$ Department of Obstetrics and Gynecology, School of Medicine, Zahedan University of Medical Sciences, Zahedan 9816743111, Iran \\ ${ }^{4}$ Department of Biology, University of Sistan and Baluchestan, Zahedan 9816743111, Iran
}

Correspondence should be addressed to Milad Mohammadoo-Khorasani; miladkh24@yahoo.com

Received 20 February 2014; Accepted 7 April 2014; Published 28 April 2014

Academic Editor: Egle Bytautiene

Copyright (C) 2014 Saeedeh Salimi et al. This is an open access article distributed under the Creative Commons Attribution License, which permits unrestricted use, distribution, and reproduction in any medium, provided the original work is properly cited.

\begin{abstract}
Preeclampsia (PE) is a pregnancy-specific disorder that results in maternal mortality and morbidity. Growing evidence indicated that cytokines are involved in the pathogenesis of PE and interleukin-4 VNTR polymorphism could be implicated in altering the PE risk. The aim of this study was to evaluate the possible association between IL-4 VNTR polymorphism and susceptibility to PE in Iranian population for the first time. Genetic polymorphism was evaluated in $192 \mathrm{PE}$ and 186 healthy control women by polymerase chain reaction method. We found that the VNTR polymorphism of IL-4 gene has significantly increased the risk of preeclampsia (RP2/RP1 versus RP1/RP1, OR, 2.8 [95\% CI, 1.7 to 8.8]; $P=0.0001$ and RP2/RP2 versus RP1/RP1; $P=0.002$ ). The results showed that carriage of IL-4 VNTR RP2 allele has positive association with preeclampsia susceptibility.
\end{abstract}

\section{Introduction}

Preeclampsia (PE) is the most common encountered complication of pregnancy and a public health problem and leads to maternal and neonatal mortality worldwide [1]. This complication is mostly characterized by new onset of hypertension and proteinuria after 20 weeks of gestation. In addition, the PE patients may show signs of renal malfunction, liver disease, and hematological disturbances [24]. Despite extensive studies, the basic etiology of PE is still unknown. However, it is confirmed that PE is a multifactorial disorder with a familial predisposition which indicates a genetic contribution [5]. During the pregnancy, there is a shift in immune cells response, T helper 1 (Th1) to T helper 2 (Th2), for favorable implantation, thus inducing maternal tolerance and suppression [6]. In women with PE some of the cytokines released by these cells have been found to be elevated, which could be markers for progression of this syndrome [7]. In this regard, some studies indicated that plasma concentration of proinflammatory cytokines such as TNF- $\alpha$, IL-6, and IL-1 $\beta$ which are the main cytokines released by Thl is higher in patients with $\mathrm{PE}$ in comparison to normotensive pregnant women [8-10]. Studies suggested that plasma levels of antiinflammatory cytokines, including IL- 4 as a critical cytokine of Th2, have decreased in PE patients [11, 12]. Interleukin4 is the main cytokine of $\mathrm{T}$ helper 2 lymphocytes, which has a key role in regulation of humoral immune responses [13]. The production of this anti-inflammatory cytokine should increase during pregnancy. Thus, the function of immune system alters during PE. Interleukin-4 (IL-4) gene is mapped within the cytokine gene cluster on chromosome $5 \mathrm{q} 31.1$ [14] and there is a $70 \mathrm{bp}$ variable number of tandem repeat (VNTR) polymorphism in its third intron which could change the expression level of IL-4 gene [15]. This VNTR polymorphism contains three alleles: RP1 allele, with three repeats, RP2 allele, with two repeats, and RP3 allele, with four repeats. The frequency of RP1 allele is higher than RP2 alleles. Likewise, RP3 allele is scarce that has been detected in few populations [16]. 
Although various genetic polymorphisms have been identified as susceptible markers for PE, there is only one published report about the association between IL-4 -590 C $>\mathrm{T}$ polymorphism and PE susceptibility. To the best of our knowledge the present study is the first report which aimed to investigate the probable association between IL-4 VNTR polymorphism and the risk of preeclampsia.

\section{Material and Methods}

2.1. Population Study. Ethical committee approval was received, and informed consent was obtained from patients and control women before beginning of the study. All individuals were recruited from the Department of Obstetrics and Gynecology of Ali-ebn-Abitaleb educational hospital of Zahedan University of Medical Sciences from 2012 to 2013. This case-control study included 192 women with PE (aged $27.5 \pm 7$ years) and 186 unrelated healthy controls (aged 26.8 \pm 6.4 years).

Preeclampsia was diagnosed according to clinical findings of increased blood pressure $(\geq 140 \mathrm{mmHg}$ systolic or $\geq 90 \mathrm{mmHg}$ diastolic on 2 or more measurements at least $6 \mathrm{~h}$ apart) and proteinuria $\geq 0.3 \mathrm{~g} / 24 \mathrm{~h}$ or $\geq+1$ on a urine dipstick after 20 weeks of gestation [17]. Exclusion criteria included twin or multiple pregnancies or any evidence of previous medical disease. Women who were affected by systemic, infectious, cardiac, and renal diseases and also systemic lupus erythematosus were excluded. The healthy state of control group was determined by medical history. None of PE patients and healthy controls had any prior history of hypertension. Early-onset PE is usually defined as PE that develops before 34 weeks of gestation, whereas late-onset PE develops at or after 34 weeks of gestation. Severe PE was defined either as severe hypertension (SBP $>160 \mathrm{mmHg}$ or DBP $>110 \mathrm{mmHg}$ ) or severe proteinuria (5 g protein in a $24 \mathrm{~h}$ urine collection).

2.2. Genomic DNA Extraction and Genotyping. The DNA analysis was performed at Cellular and Molecular Research Center (Zahedan, Iran). Blood samples were collected in $2 \mathrm{~mL}$ Na-EDTA tubes from patients and healthy controls. Genomic DNA was extracted from peripheral blood leukocytes by salting-out method. The $70 \mathrm{bp}$ VNTR region of IL4 gene intron 3 was analyzed by polymerase chain reaction (PCR). Two oligonucleotide primers are as follows: forward: $5^{\prime}$ AGGCTGAAAGGGGGAAAGC-3' and reverse: $5^{\prime}$ CTGTTCACCTCAACTGCTCC- $3^{\prime}$.

PCR reaction was performed in a $25 \mu \mathrm{L}$ final volume that contained $25 \mathrm{pmol}$ of each primer, $0.1 \mathrm{mmol}$ dNTP (Fermentas, Lithuania), $0.5 \mu \mathrm{g}$ genomic DNA, $1.5 \mathrm{mM} \mathrm{MgCl}$, $2.5 \mu \mathrm{L}$ of PCR buffer and 1.5 unit of Taq DNA polymerase (Fermentas, Lithuania) according to the following protocol: initial denaturation at $94^{\circ} \mathrm{C}$ for $5 \mathrm{~min}, 30$ cycles of denaturation at $94^{\circ} \mathrm{C}$ for $50 \mathrm{~s}$, annealing at $61^{\circ} \mathrm{C}$ for $30 \mathrm{~s}$, extension at $72^{\circ} \mathrm{C}$ for $45 \mathrm{~s}$; and final extension at $72^{\circ} \mathrm{C}$ for 5 minutes. PCR products were separated by electrophoresis on a $1.5 \%$ agarose gel and visualized by ethidium bromide staining.

2.3. Statistical Analysis. Data was analyzed using the statistical SPSS v.18 software. The differences between groups were analyzed by independent sample $t$-test, $\chi^{2}$ test, or Fisher's exact test, whenever appropriate. Direct gene counting method was used to determine the allele frequency. The genotypes and alleles frequency were compared between PE patients and controls by $\chi^{2}$ test and Fisher's exact test. The odds ratio (OR) and $95 \%$ confidence intervals $(95 \% \mathrm{CI})$ were also estimated. Values of $P<0.05$ were considered statistically significant.

\section{Results}

Demographic data of the PE patients and control group are shown in Table 1. There were no differences in the maternal age and birth weight between two groups. However, PE women had significantly higher systolic and diastolic blood pressures than control group. Moreover, gestational age and primiparity were significantly different between patients and controls $(P<0.05)$. The distribution of three ethnic groups (Balouch, Fars, and Afghan) was significantly different between PE patients and control group $(P=0.003)$, and the risk of PE was 1.7-fold greater in Afghan women in comparison with Balouch and Fars women (OR, 1.7 [95\% CI, 1 to 2.8 ]; $P=0.003$ ). There were 44 patients with early-onset $\mathrm{PE}$ and 148 patients with late-onset PE. There were also 50 patients with severe PE and 142 patients with mild PE.

The genotype and allele frequencies of IL-4 VNTR polymorphism are shown in Table 2.

The genotypic and allelic frequencies were statistically different between these two groups and the risk of PE was higher in individuals with RP1/RP2 genotype in comparison to those with RP1/RP1 genotype (OR, 2.8 [95\% CI, 1.7 to 8.8]; $P=0.0001)$. Furthermore, the frequency of RP2/RP2 genotype in $\mathrm{PE}$ patient was more than control group and this difference was significant $P=0.002$. In addition, the frequency of RP2 allele was significantly higher in PE patients. Therefore, this allele could be a risk factor for PE (OR, 3.1 [95\% CI, 1.91 to 4.93]; $P=0.0001$ ).

The genotypic and allelic frequencies of IL-4 VNTR polymorphism did not differ between early-onset PE and lateonset PE. In addition, IL-4 VNTR polymorphism was not associated with PE severity. There were not any differences in genotypes and alleles of IL-4 VNTR polymorphism among three ethnic groups (Baluch, Persian, and Afghan).

\section{Discussion}

The immune system has a close relation with pregnancy from implantation to placentation [18] and immunomodulation is prerequisite for successful pregnancy. Hence, the fetus can be protected from maternal immune-cell attacks. Recent studies showed that the altered immune system could lead to PE and several epidemiological findings and animal models support this idea. Immune maladaptation has been reported in PE too [19]. There are multiple factors which develop PE and play key roles in its pathophysiology. Several studies demonstrated that Th1/Th2 balance has changed in patients affected with PE [20-22] and plasma levels of proinflammatory cytokines in $\mathrm{PE}$ pregnant women are higher in comparison with normal pregnant women [22-24]. Furthermore, some evidences indicated that serum levels of interlukine- 4 in PE patients 
TABLE 1: Demographic characteristics of PE patients and controls.

\begin{tabular}{|c|c|c|c|c|}
\hline Variable & $\begin{array}{c}\text { Controls } \\
n=186\end{array}$ & $\begin{array}{c}\text { PE patients } \\
n=192\end{array}$ & $P$ value & OR $(95 \% \mathrm{CI})$ \\
\hline Maternal age (years) & $26.7 \pm 6.4$ & $27.5 \pm 7$ & NS & \\
\hline Gestation age (weeks) & $38.5 \pm 2.4$ & $37.1 \pm 3.5$ & 0.001 & \\
\hline Birth weight & $2932 \pm 486$ & $2801 \pm 23$ & NS & \\
\hline SBP & $114 \pm 9$ & $143.7 \pm 22$ & 0.0001 & \\
\hline DBP & $71.3 \pm 11.5$ & $90.8 \pm 13.9$ & 0.0001 & \\
\hline Primiparity $n(\%)$ & $57(30)$ & $84(44)$ & 0.003 & $1.9(1.2-2.8)$ \\
\hline Family history of PE, $n(\%)$ & $61(33)$ & $77(40)$ & NS & \\
\hline \multicolumn{5}{|l|}{ Race, $n(\%)$} \\
\hline Balouch & $81(43.5)$ & $81(42)$ & & 1 \\
\hline Fars & $70(37.6)$ & $52(27)$ & 0.13 & $0.7(0.5-1.1)$ \\
\hline Afghan & $35(18.8)$ & $59(31)$ & 0.003 & $1.7(1-2.8)$ \\
\hline
\end{tabular}

NS: not significant.

TABLE 2: Genotypes and alleles frequency of the IL-4 VNTR polymorphism in PE patients and controls.

\begin{tabular}{lcccc}
\hline Genotype & $\begin{array}{c}\text { Case } \\
(=192 \\
(\%)\end{array}$ & $\begin{array}{c}\text { Control } \\
N=186 \\
(\%)\end{array}$ & $P$ value & OR (95\% CI) \\
\hline RP1/RP1 & $128(66.7)$ & $161(86.6)$ & Ref $=1$ & \\
RP1/RP2 & $56(29.1)$ & $25(13.6)$ & 0.0001 & $2.8(1.7-8.8)$ \\
RP2/RP2 & $8(4.2)$ & $0(0)$ & 0.002 & - \\
Allele & & & & \\
RP1 & $312(81.2)$ & $347(93.3)$ & Ref $=1$ & \\
RP2 & $72(18.8)$ & $25(6.7)$ & 0.0001 & $3.1(1.91-4.93)$ \\
\hline
\end{tabular}

have decreased. Interleukin- 4 belongs to cytokines released by $\mathrm{Th} 2$ and acts as an anti-inflammatory cytokine $[25,26]$.

Recently, the association of several proinflammatory and anti-inflammatory gene polymorphisms such as IL-10 [27], IL-1 $\beta$ [28], IL-6 [29], IL-4 [30], IL1-RA [31], and TNF- $\alpha$ [32] genes and PE susceptibility has been investigated and in many populations this association was statistically significant.

In the present study we found that RP1/RP2 and RP2/RP2 genotypes and RP2 allele could be risk factors in predisposing to preeclampsia in our population. The RP1/RP2 and $\mathrm{RP} 2 / \mathrm{RP} 2$ genotypes were observed more frequently in $\mathrm{PE}$ patients than controls (29.1\% versus $13.6 \%$ and $4.2 \%$ versus $0 \%$, resp.). Moreover, the RP2 allele was found more prevalent in preeclampsia patients in comparison with healthy subjects $(18.8 \%$ versus $6.7 \%)$ and may enhance the risk of preeclampsia by $3.1-$ fold.

IL-4 VNTR polymorphism located in intron 3 of IL-4 gene and could alter messenger ribonucleic acid splicing, which leads to different splice variants [33]. Some studies suggested that RP2/RP2 genotype is associated with low expression of this cytokine [34]. However, another study showed the possible association between RP1 allele and higher expression of the IL-4 [35]. This finding supports this fact that serum level of interlukine- 4 in PE patients has decreased.
Up to now, the association of IL-4 VNTR polymorphism with several diseases such as leiomyoma [36], cervical cancer [37], breast cancer [38], end-stage renal disease [39], SLE [40] oral cancer [41], and Kawasaki disease [42] has been investigated. Hsieh et al. indicated lack of association between VNTR polymorphism of IL-4 and leiomyoma disease [36]. However, allelic frequency of RP2 in patients affected with leiomyoma was higher than normal individuals. Shekari et al. showed that genotype frequencies of RP1/RP2 among patients affected with cervical cancer were significantly higher than healthy women [37]. There is only one published report about the association of $\mathrm{C}>\mathrm{T}$ polymorphism of IL-4 gene with PE which was conducted by Fraser et al. in UK. They found a marked trend for the association between the IL-4 -590 C > T polymorphism and PE [30].

These observations supported the hypothesis that immunological, inflammatory, and anti-inflammatory processes could play key roles in PE development.

Our study suffered from some limitations, for example, low sample size, environmental conditions, and different ethnic groups. For a real understanding of what was said, it is suggested to conduct more extensive studies on larger numbers of people of a community and other ethnic groups from the viewpoint of genetic and environmental factors in order to discuss the role of IL-4VNTR polymorphism in PE pathogenesis more firmly.

In conclusion, we found higher frequency of RP1/RP2 and $\mathrm{RP} 2 / \mathrm{RP} 2$ genotypes in comparison to RP1/RP1 genotype in PE patients.

\section{Conflict of Interests}

The authors declare that they have no conflict of interests.

\section{Acknowledgments}

The authors thank the patients and normal controls for participating in this study and Zahedan Deputy of Research Affairs for funding this project. 


\section{References}

[1] N. Al-Jameil, F. A. Khan, M. F. Khan, and H. Tabassum, "A brief overview of preeclampsia," Journal of Clinical Medicine Research, vol. 6, no. 1, pp. 1-7, 2014.

[2] C. W. Redman and I. L. Sargent, "Latest advances in understanding preeclampsia," Science, vol. 308, no. 5728, pp. 1592-1594, 2005.

[3] I. E. Stillman and S. A. Karumanchi, "The glomerular injury of preeclampsia," Journal of the American Society of Nephrology, vol. 18, no. 8, pp. 2281-2284, 2007.

[4] J. R. Wilczynski, H. Tchórzewski, E. Glowacka et al., "Cytokine secretion by decidual lymphocytes in transient hypertension of pregnancy and pre-eclampsia," Mediators of Inflammation, vol. 11, no. 2, pp. 105-111, 2002.

[5] A. M. A. Lachmeijer, G. A. Dekker, G. Pals, J. G. Aarnoudse, L. P. ten Kate, and R. Arngrímsson, "Searching for preeclampsia genes: the current position," European Journal of Obstetrics \& Gynecology and Reproductive Biology, vol. 105, no. 2, pp. 94-113, 2002.

[6] T. G. Wegmann, H. Lin, L. Guilbert, and T. R. Mosmann, "Bidirectional cytokine interactions in the maternal-fetal relationship: is successful pregnancy a $\mathrm{T}_{\mathrm{H}} 2$ phenomenon?" Immunology Today, vol. 14, no. 7, pp. 353-356, 1993.

[7] F. Mohajertehran, J. T. Afshari, Z. Rezaieyazdi, and N. Ghomian, "Association of single nucleotide polymorphisms in the human tumor necrosis factor- $\alpha$ and interleukin $1-\beta$ genes in patients with pre-eclampsia," Iranian Journal of Allergy, Asthma, and Immunology, vol. 11, no. 3, pp. 224-229, 2012.

[8] Y. Jonsson, M. Rubèr, L. Matthiesen et al., "Cytokine mapping of sera from women with preeclampsia and normal pregnancies," Journal of Reproductive Immunology, vol. 70, no. 1-2, pp. 83-91, 2006.

[9] D. F. Benyo, A. Smarason, C. W. G. Redman, C. Sims, and K. P. Conrad, "Expression of inflammatory cytokines in placentas from women with preeclampsia," The Journal of Clinical Endocrinology \& Metabolism, vol. 86, no. 6, pp. 2505-2512, 2001.

[10] I. A. Greer, F. Lyall, T. Perera, F. Boswell, and L. M. Macara, "Increased concentrations of dytokines interleukin and interleukin-1 receptor antagonist in plasma of women with preeclampsia: a mechanism for endothelial dysfunction?" Obstetrics \& Gynecology, vol. 84, no. 6, pp. 937-940, 1994.

[11] S. E. Kopriva, V. L. Chiasson, B. M. Mitchell, and P. Chatterjee, "TLR3-induced placental miR-210 down-regulates the STAT6/interleukin-4 pathway," PloS ONE, vol. 8, no. 7, Article ID e67760, 2013.

[12] L. Arriaga-Pizano, L. Jimenez-Zamudio, F. Vadillo-Ortega, A. Martinez-Flores, T. Herrerias-Canedo, and C. HernandezGuerrero, "The predominant Thl cytokine profile in maternal plasma of preeclamptic women is not reflected in the choriodecidual and fetal compartments," Journal of the Society for Gynecologic Investigation, vol. 12, no. 5, pp. 335-342, 2005.

[13] N. Rezaei, A. Aghamohammadi, M. Mahmoudi et al., "Association of IL-4 and IL-10 gene promoter polymorphisms with common variable immunodeficiency," Immunobiology, vol. 215, no. 1, pp. 81-87, 2010.

[14] A. N. Jha, V. K. Singh, N. Kumari et al., "IL-4 haplotype -590T, -34 T and intron-3 VNTR R2 is associated with reduced malaria risk among ancestral Indian tribal populations," PloS ONE, vol. 7, no. 10, Article ID e48136, 2012.

[15] N. Buchs, T. Silvestri, F. S. di Giovine et al., "IL-4 VNTR gene polymorphism in chronic polyarthritis. The rare allele is associated with protection against destruction," Rheumatology, vol. 39, no. 10, pp. 1126-1131, 2000.

[16] R. Mout, R. Willemze, and J. E. Landegent, "Repeat polymorphisms in the interleukin-4 gene (IL4)," Nucleic Acids Research, vol. 19, no. 13, article 3763, 1991.

[17] E. Tabatabai, S. Salimi, M. Mohammadoo-Khorasani et al., "KE and EE genotypes of ICAM-1 gene K469E polymorphism is associated with severe preeclampsia," Disease Markers, vol. 2014, Article ID 124941, 5 pages, 2014.

[18] S. Saito, A. Shiozaki, A. Nakashima, M. Sakai, and Y. Sasaki, "The role of the immune system in preeclampsia," Molecular Aspects of Medicine, vol. 28, no. 2, pp. 192-209, 2007.

[19] R. Pijnenborg, J. M. Bland, W. B. Robertson, and I. Brosens, "Uteroplacental arterial changes related to interstitial trophoblast migration in early human pregnancy," Placenta, vol. 4, no. 4, pp. 397-413, 1983.

[20] S. Saito and M. Sakai, "Th1/Th2 balance in preeclampsia," Journal of Reproductive Immunology, vol. 59, no. 2, pp. 161-173, 2003.

[21] D. Darmochwal-Kolarz, B. Leszczynska-Gorzelak, J. Rolinski, and J. Oleszczuk, "T helper 1- and T helper 2-type cytokine imbalance in pregnant women with pre-eclampsia," European Journal of Obstetrics \& Gynecology and Reproductive Biology, vol. 86, no. 2, pp. 165-170, 1999.

[22] G. Toldi, J. Rigó Jr., B. Stenczer, B. Vásárhelyi, and A. Molvarec, "Increased prevalence of IL-17-producing peripheral blood lymphocytes in pre-eclampsia," American Journal of Reproductive Immunology, vol. 66, no. 3, pp. 223-229, 2011.

[23] Y. Jonsson, M. Rubèr, L. Matthiesen et al., "Cytokine mapping of sera from women with preeclampsia and normal pregnancies," Journal of Reproductive Immunology, vol. 70, no. 1, pp. 83-91, 2006.

[24] A. Szarka, J. Rigó Jr., L. Lázár, G. Beko, and A. Molvarec, "Circulating cytokines, chemokines and adhesion molecules in normal pregnancy and preeclampsia determined by multiplex suspension array," BMC Immunology, vol. 11, no. 1, article 59, 2010.

[25] R. Wei and G. M. Jonakait, "Neurotrophins and the antiinflammatory agents interleukin-4 (IL-4), IL- 10, IL-11 and transforming growth factor- $\beta 1$ (TGF- $\beta 1$ ) down-regulate $\mathrm{T}$ cell costimulatory molecules B7 and CD40 on cultured rat microglia," Journal of Neuroimmunology, vol. 95, no. 1, pp. 8-18, 1999.

[26] K. Ghoreschi, P. Thomas, S. Breit et al., "Interleukin-4 therapy of psoriasis induces Th2 responses and improves human autoimmune disease," Nature Medicine, vol. 9, no. 1, pp. 40-46, 2002.

[27] E. Kamali-Sarvestani, S. Kiany, B. Gharesi-Fard, and M. Robati, "Association study of IL-10 and IFN- $\gamma$ gene polymorphisms in Iranian women with preeclampsia," Journal of Reproductive Immunology, vol. 72, no. 1, pp. 118-126, 2006.

[28] L. A. Hefler, C. B. Tempfer, and A. R. Gregg, "Polymorphisms within the interleukin-1 $\beta$ gene cluster and preeclampsia," Obstetrics \& Gynecology, vol. 97, no. 5, pp. 664-668, 2001.

[29] F. Stonek, E. Hafner, M. Metzenbauer et al., "Absence of an association of tumor necrosis factor (TNF)- $\alpha$ G308A, interleukin- 6 (IL-6) G174C and interleukin-10 (IL-10) G1082A polymorphism in women with preeclampsia," Journal of Reproductive Immunology, vol. 77, no. 1, pp. 85-90, 2008.

[30] R. Fraser, J. J. Walker, U. V. Ekbote, K. L. Martin, P. McShane, and N. M. Orsi, "Interleukin-4 $-590(\mathrm{C}>\mathrm{T})$, toll-like receptor$2+2258(\mathrm{G}>\mathrm{A})$ and matrix metalloproteinase-9 -1562 (C>T) 
polymorphisms in pre-eclampsia," BJOG: An International Journal of Obstetrics \& Gynaecology, vol. 115, no. 8, pp. 1052-1055, 2008.

[31] A. M. A. Lachmeijer, M. P. Nosti-Escanilla, E. B. Bastiaans et al., "Linkage and association studies of IL1b and IL1RN gene polymorphisms in preeclampsia," Hypertension in Pregnancy, vol. 21, no. 1, pp. 23-38, 2002.

[32] A. Molvarec, Á. Jermendy, B. Nagy et al., "Association between tumor necrosis factor (TNF)- $\alpha$ G-308A gene polymorphism and preeclampsia complicated by severe fetal growth restriction," Clinica Chimica Acta, vol. 392, no. 1, pp. 52-57, 2008.

[33] A. Inanir, S. Tural, S. Yigit et al., "Association of IL-4 gene VNTR variant with deep venous thrombosis in Behçet's disease and its effect on ocular involvement," Molecular Vision, vol. 19, pp. 675683, 2013.

[34] S. Cabantous, B. Poudiougou, A. A. Oumar et al., "Genetic evidence for the aggravation of plasmodium falciparum malaria by interleukin 4," Journal of Infectious Diseases, vol. 200, no. 10, pp. 1530-1539, 2009.

[35] G. F. Fang, X. Y. Fan, and F. H. Shen, “The relationship between polymorphisms of interleukin-4 gene and silicosis," Biomedical and Environmental Sciences, vol. 24, no. 6, pp. 678-682, 2011.

[36] Y.-Y. Hsieh, C.-C. Chang, C.-H. Tsai, C.-C. Lin, and F.-J. Tsai, "Interleukin (IL)-12 receptor $\beta 1$ codon $378 \mathrm{G}$ homozygote and allele, but not IL-1 ( $\beta$-511 promoter, 3953 exon 5, receptor antagonist), IL-2 114, IL-4-590 intron 3, IL-8 3 '-UTR 2767, and IL-18 105, are associated with higher susceptibility to leiomyoma," Fertility and Sterility, vol. 87, no. 4, pp. 886-895, 2007.

[37] M. Shekari, D. M. Kordi-Tamandani, K. MalekZadeh, R. C. Sobti, S. Karimi, and V. Suri, "Effect of anti-inflammatory (IL-4, IL-10) cytokine genes in relation to risk of cervical carcinoma," American Journal of Clinical Oncology, vol. 35, no. 6, pp. 514-519, 2012.

[38] R. Konwar, P. Chaudhary, S. Kumar, D. Mishra, N. Chattopadhyay, and H. K. Bid, "Breast cancer risk associated with polymorphisms of IL-1RN and IL-4 gene in Indian women," Oncology Research, vol. 17, no. 8, pp. 367-372, 2009.

[39] R. D. Mittal and P. K. Manchanda, "Association of interleukin (IL)-4 intron-3 and IL-6 -174 G/C gene polymorphism with susceptibility to end-stage renal disease," Immunogenetics, vol. 59, no. 2, pp. 159-165, 2007.

[40] M.-C. Wu, C.-M. Huang, J. J. P. Tsai, H.-Y. Chen, and F.-J. Tsai, "Polymorphisms of the interleukin-4 gene in Chinese patients with systemic lupus erythematosus in Taiwan," Lupus, vol. 12, no. 1, pp. 21-25, 2003.

[41] M.-H. Tsai, W.-C. Chen, C.-H. Tsai, L.-W. Hang, and F.-J. Tsai, "Interleukin-4 gene, but not the interleukin-1 $\beta$ gene polymorphism, is associated with oral cancer," Journal of Clinical Laboratory Analysis, vol. 19, no. 3, pp. 93-98, 2005.

[42] S.-F. Wu, J.-S. Chang, L. Wan, C.-H. Tsai, and F.-J. Tsai, "Association of IL-1Ra gene polymorphism, but no association of IL-1 $\beta$ and IL-4 gene polymorphisms, with Kawasaki disease," Journal of Clinical Laboratory Analysis, vol. 19, no. 3, pp. 99-102, 2005. 

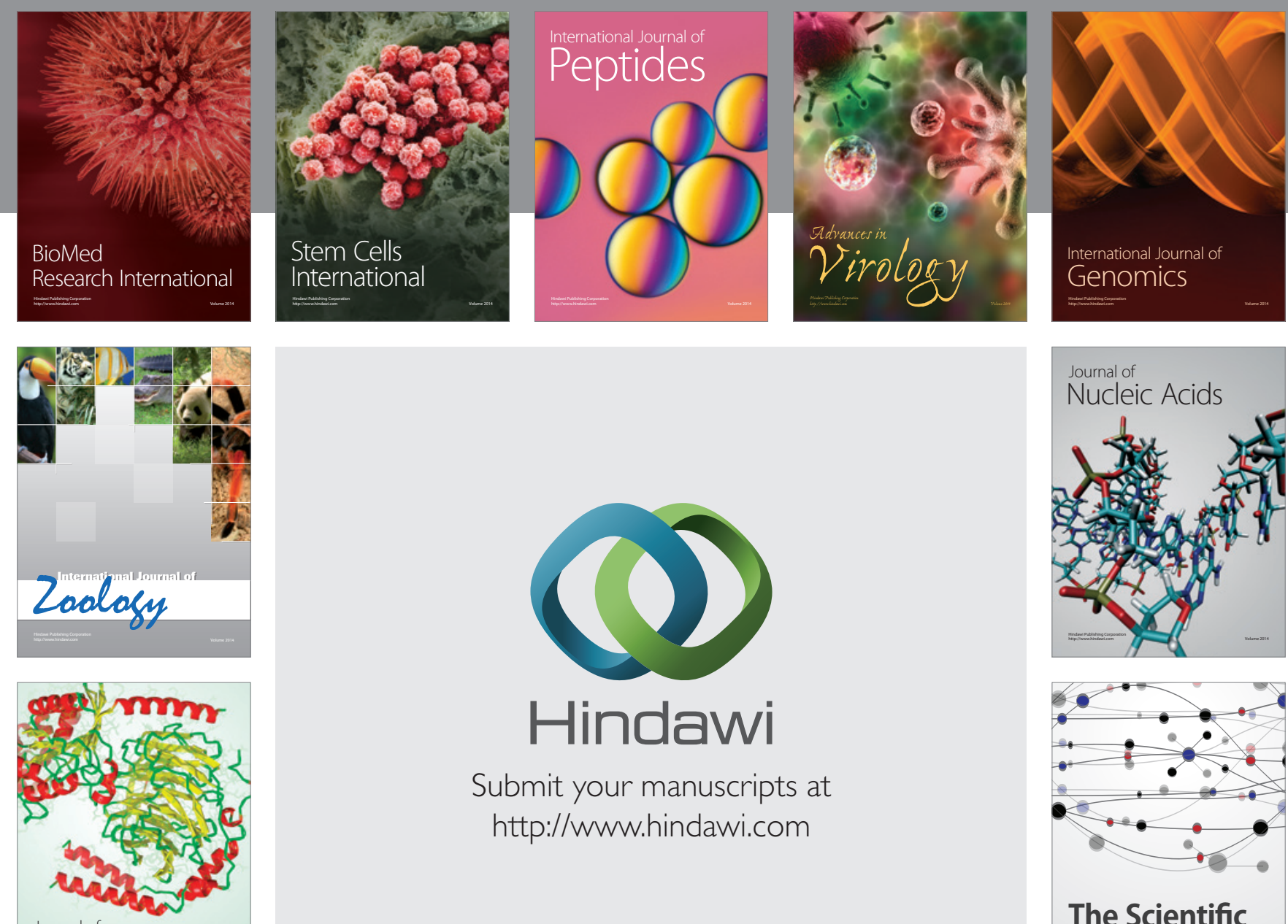

Submit your manuscripts at

http://www.hindawi.com

Journal of
Signal Transduction
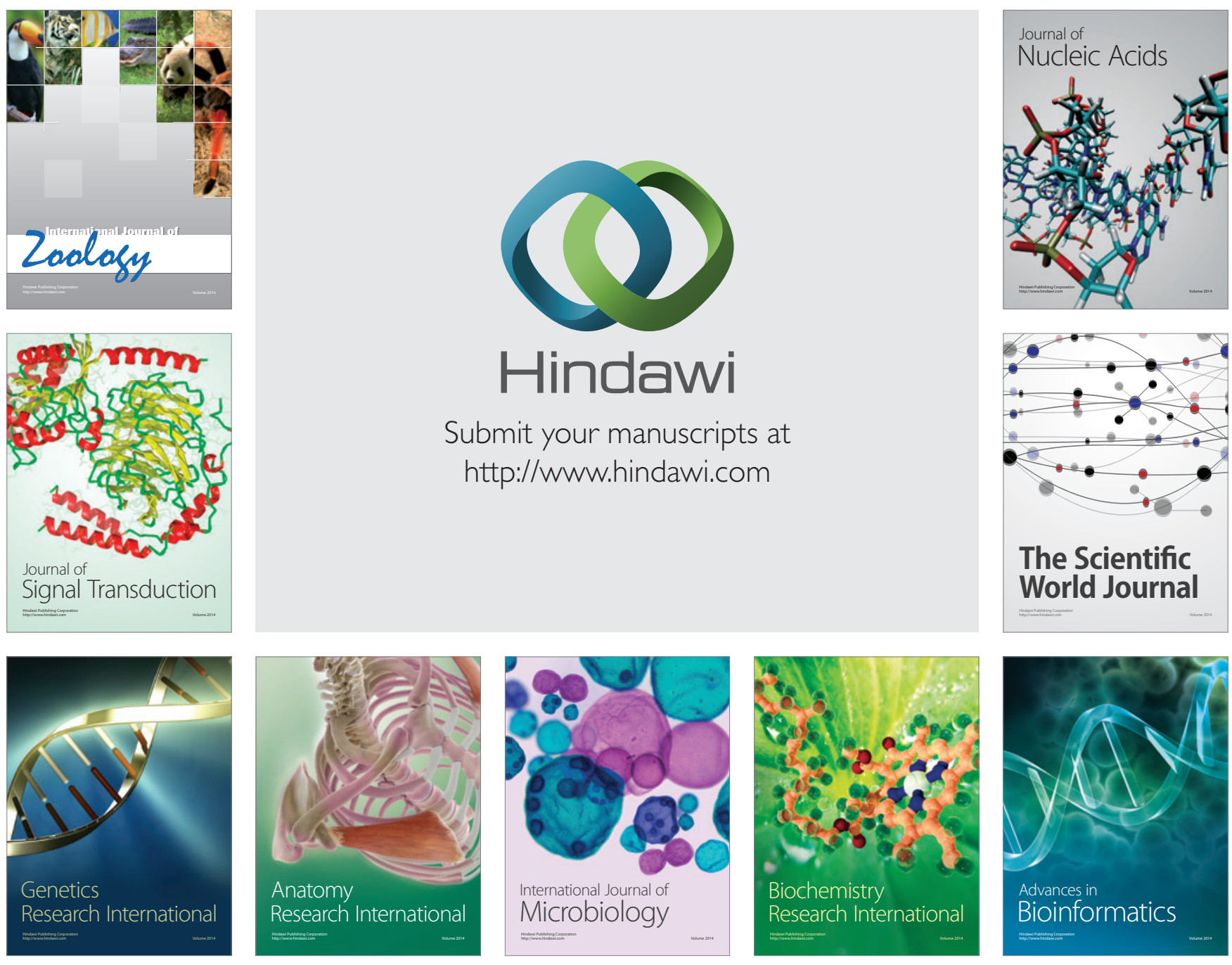

The Scientific World Journal
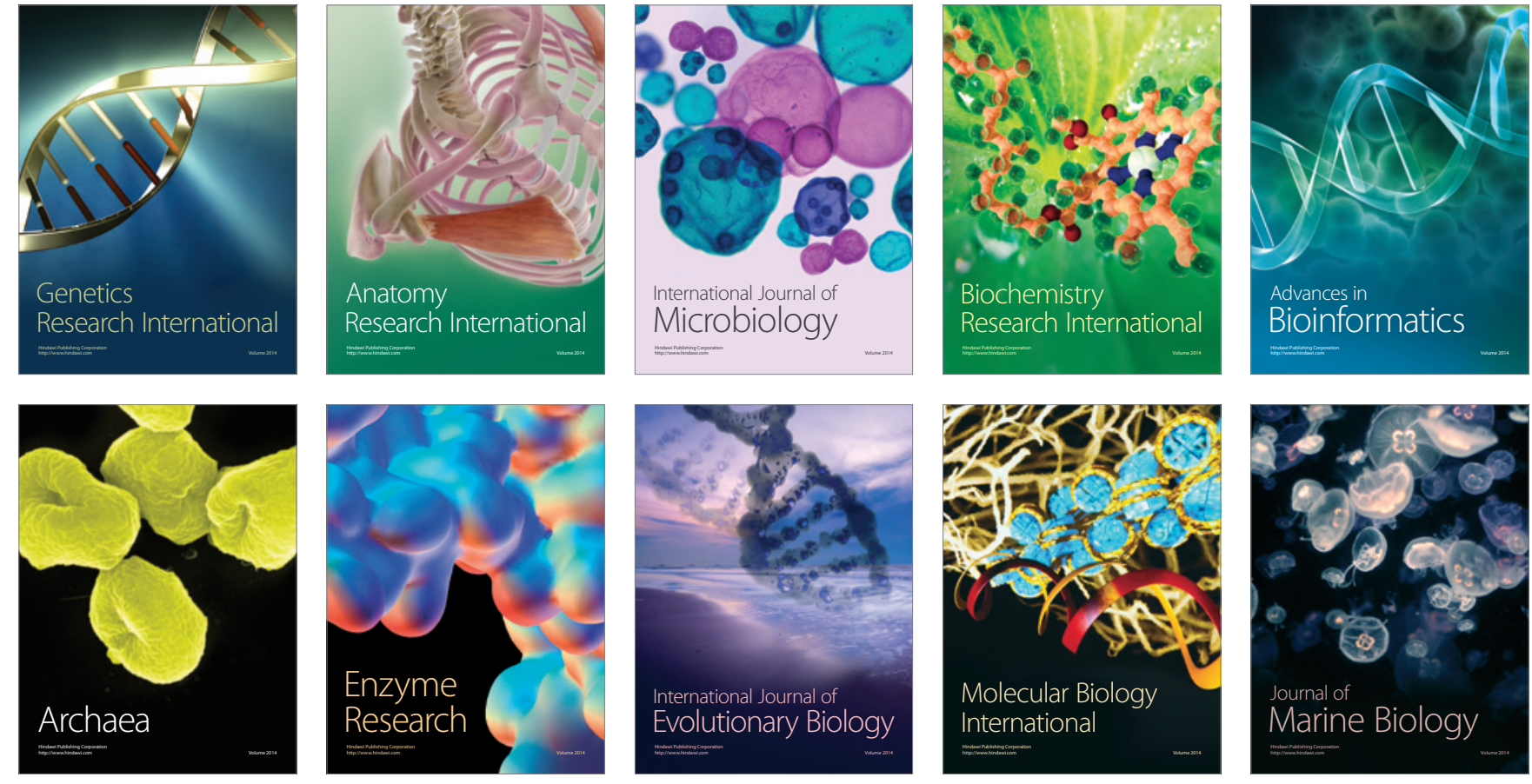